\title{
A LIBERDADE DE CONSCIÊNCIA E SUA IMPLICAÇÃO NA CONCEPÇÃO EDUCACIONAL DE CONDORCET, HUMBOLDT E MILL
}

Itamaragiba Chaves Xavier Elomar Callegaro Tambara ${ }^{1}$

\section{RESUMO}

O objetivo do presente artigo é compreender qual a concepção educacional de Condorcet, Humboldt e Mill através da análise da categoria liberdade de consciência. O referencial teórico-metodológico empregado é o materialismo histórico. As fontes utilizadas são: Esboço de um quadro histórico dos progressos do espírito humano (CONDORCET, 1993), Bosquejo de un cuadro histórico de los progresos del espíritu humano y otros textos (CONDORCET, 1997), Cinco memórias sobre a instrução pública (CONDORCET, 2008) e Escritos sobre instrução pública: Condorcet (CONDORCET, 2010), Os limites da acção do estado (HUMBOLDT, 1990), Princípios de economia política (MILL, 1988) e Sobre a liberdade (MILL, 1991). Pode-se concluir que a liberdade de consciência influenciou de forma diferente a concepção de escola pública e laica em cada um dos autores.

Palavras-chave: Liberdade de consciência; Educação; Condorcet; Humboldt; Mill.

\section{THE FREEDOM OF CONSCIENCE AND ITS IMPLICATION IN THE EDUCATIONAL CONCEPTION OF CONDORCET, HUMBOLDT AND MILL}

\begin{abstract}
The objective of this paper is to understand the educational conception of Condorcet, Humbolt and Mill through the analysis of the category freedom of conscience. The theoretical and methodological referential utilized is the historical materialism. The sources used are: Esboço de um quadro histórico dos progressos do espírito humano (CONDORCET, 1993), Bosquejo de un cuadro histórico de los progresos del espíritu humano y otros textos (CONDORCET, 1997), Cinco memórias sobre a instrução pública (CONDORCET, 2008) e Escritos sobre instrução pública: Condorcet (CONDORCET, 2010), Os limites da acção do estado (HUMBOLDT, 1990), Princípios de economia política (MILL, 1988) e Sobre a liberdade (MILL, 1991). It can be concluded that the freedom of conscience influenced in a different way the conception of public school and lay school in each one of the authors.

Keywords: Freedom of conscience; Education; Condorcet; Humboldt; Mill.
\end{abstract}

\section{Introdução}

Através da análise da categoria liberdade de consciência se buscará compreender a defesa ou não da escola pública e laica na obra de clássicos do liberalismo: Condorcet, Humboldt e Mill.

A justificativa da escolha da categoria liberdade de consciência está na centralidade epistemológica que a mesma apresenta para o liberalismo. Segundo Barros (1986, p. 57) o liberalismo "se deduz inteiro a partir do ideal de liberdade de consciência". E conforme Chaves (2007, p. 8), "a liberdade é, para o liberalismo, o bem supremo no contexto da relação do individuo com seus semelhantes na sociedade, e no contexto de sua relação com o Estado". 
O referencial teórico-metodológico empregado está pautado em: Althusser (1974), Gorender (1982), Manacorda (2010), Marx (2009), Marx e Engels (1986), Ponce (1996), Saviani (2008) e Tambara (1995 e 2000). As fontes utilizadas como representativas da produção teórica dos autores analisados foram: Esboço de um quadro histórico dos progressos do espírito humano (CONDORCET, 1993), Bosquejo de un cuadro histórico de los progresos del espíritu humano y otros textos (CONDORCET, 1997), Cinco memórias sobre a instrução pública (CONDORCET, 2008) e Escritos sobre instrução pública: Condorcet (CONDORCET, 2010), Os limites da acção do estado (HUMBOLDT, 1990), Princípios de economia política (MILL, 1988) e Sobre a liberdade (MILL, 1991).

$\mathrm{O}$ artigo está dividido em três partes. Na primeira, será analisado Kant, "Resposta a pergunta: que é o iluminismo" (2004). Apesar de Kant não ser um dos autores analisados no debate sobre a escola pública e laica, ele é importante para a compreensão das categorias: "liberdade de consciência" e "formação do sujeito esclarecido e ativo", ambas presentes em Condorcet, Humboldt e Mill.

$\mathrm{Na}$ segunda parte serão analisadas as peculiares compreensões de Condorcet, Humboldt e Mill de escola pública e laica, tendo por base a categoria liberdade de consciência. Na terceira parte, denominada de palavras finais, será elaborada a crítica ao uso, pelos autores, da liberdade de consciência e o porquê da defesa ou não da escola pública e laica. Nesta parte, também, discutir-se-á como as políticas públicas educacionais contemporâneas hegemônicas em nível nacional se posicionam em relação aos pressupostos liberais e neste sentido se defendem os interesses da classe trabalhadora ou reforçam os interesses do capital?

\section{Kant e o esclarecimento}

Kant define a liberdade de consciência como a capacidade de se fazer uso livre da razão e que, para isto, o sujeito precisa ser esclarecido. Segundo $\operatorname{Kant}^{2}$ (2004, p.11) esclarecimento é

a saída do homem de sua menoridade, da qual ele próprio é culpado. A menoridade é a incapacidade de fazer uso de seu entendimento sem a direção de outro indivíduo. O homem é o próprio culpado dessa menoridade se a causa dela não se encontra na falta de entendimento, mas na falta de decisão e coragem de se servir de si mesmo sem a direção de outrem. Sapere aude! Tem coragem de fazer uso de teu próprio entendimento, tal é o lema do esclarecimento.

A menoridade é o estado em que se encontra a pessoa que não faz uso de seu próprio entendimento, em que ele é o culpado por preguiça e covardia. Por outro lado, o lema do esclarecimento é sapere aude, ou seja, tenha coragem de usar o seu próprio entendimento. A principal forma de enfrentar a menoridade, que é uma das principais características da fragilidade humana, é ter coragem de pensar por si mesmo (DALBOSCO, 2011).

A saída da menoridade para a maioridade - pensar por conta própria - é resultado de um longo processo formativo, que deve ter seu início ainda na infância. Esse processo formativo da maioridade tem uma implicação pedagógica, onde a geração anterior forma a posterior. Essa formação se realiza colocando à disposição dos alunos o conhecimento acumulado, dando a esses, condições de construir o seu conhecimento, rompendo com a formação escolástica, onde o aluno é passivo no processo pedagógico. Kant coloca o aluno no centro do processo pedagógico, compreendido como sujeito ativo, onde o conhecimento, para ser significativo ao aluno, deve ser por ele produzido, uma vez que ele 
aprende melhor aquilo que ele faz. A pedagogia de Kant visa conduzir o aluno a pensar por si mesmo (DALBOSCO, 2011).

Essa formação da maioridade se completa pelo uso público da razão, que vem a ser fundamental para que se consiga atingir o esclarecimento, "o uso público da própria razão deve sempre ser livre e só ele pode levar a cabo a ilustração entre os homens" (KANT, 2004, p. 13). Para Kant (2004, p. 13), o uso público da razão é "aquele que qualquer um, enquanto erudito, dela faz perante o grande grupo do mundo letrado". Por erudito, se entende o sujeito esclarecido. O erudito é a personificação do sapere aude, é o homem que teve a coragem de pensar por si.

Parece contraditória essa afirmação de que o uso público da própria razão forma o sujeito esclarecido e, ao mesmo tempo, quem faz o uso público da razão é o erudito, que é o sujeito esclarecido. É que, para Kant, o esclarecimento não é algo a se chegar, mas algo em constante construção. E essa construção ocorre na relação com o outro, o indivíduo não se esclarece isoladamente. Na perspectiva kantiana, o esclarecimento deve ser atingido por todos e não apenas por alguns.

Outro elemento importante no pensamento de Kant é que a sua ação deve estar desligada de seus interesses, ele "é livre quando consegue se desprender de seus desejos espontâneos e não quando lhes obedece" (THOUARD, 2004, 125). É o primado da razão sobre os seus interesses particulares. Para Kant, a ação do homem livre deve ser determinada pelo dever agir e essa ação deve ter validade universal "age de tal modo que a máxima de tua vontade possa sempre valer ao mesmo tempo como princípio de uma legislação universal" (KANT, 2008, p. 51).

Esse princípio categórico determina que a ação não deva ser determinada por interesses momentâneos ou particulares, mas que tenha validade sempre e em qualquer situação, não abrindo uma exceção para ele próprio ou para outro. O sujeito livre é aquele que age independente da vontade de outros sujeitos e controla os seus interesses particulares, tendo, por determinação da sua ação, o uso livre da sua razão.

Em relação à intervenção do Estado em questões religiosas, Kant defende que o Estado deve se afastar de qualquer prescrição nessa matéria, inclusive, é contrário à tolerância religiosa, pois o que ele quer é a total liberdade religiosa aos súditos. Segundo Kant (2004, p. 17)

um príncipe que não acha indigno de si dizer que tem por dever nada prescrever aos homens em matéria de religião, mas deixa-lhes aí a plena liberdade, que, por conseguinte, recusa o arrogante nome de tolerância, é efetivamente esclarecido e merece ser encomiado pelo mundo grato e pela posteridade como aquele que, pela primeira vez, libertou o gênero humano da menoridade, pelo menos por parte do governo, e deu a cada qual a liberdade de se servir da própria razão em tudo o que é assunto de consciência.

Para finalizar a abordagem específica sobre Kant, se faz necessário uma conclusão que ressalte os temas que são importantes para o presente trabalho e que tenha relação com os demais autores que serão analisados. Pode-se afirmar que o sujeito esclarecido de Kant, o qual atingiu a maioridade, é o que pensa e age por si mesmo. O sujeito esclarecido segue somente a sua razão, não se submete nas suas escolhas a outro sujeito ou instituição. A formação desse sujeito esclarecido implica em uma pedagogia que coloca o aluno no centro da produção de seu próprio conhecimento. Além disso, é fundamental ser livre para fazer o uso público da razão e que o esclarecimento e a participação nos rumos da 
humanidade não se restrinjam a uma parcela da população. Essa concepção de homem esclarecido gera o sujeito ativo, que participa no destino da sociedade.

\section{A liberdade de consciência e sua implicação na concepção educacional de Condorcet, Humboldt e Mill.}

Nessa parte do trabalho será analisada a implicação da liberdade de consciência na concepção educacional de Condorcet, Humboldt e Mill.

A análise será iniciada por Condorcet, autor que defende a liberdade de consciência e tem a instrução como um elemento central para alcançá-la. Ao tratar da instrução primária, defende que essa deve dar ao aluno conhecimento suficiente "para se conduzir por si mesmo" (CONDORCET, 2010, p. 25). Pode-se observar a presença do homem esclarecido de Kant, aquele que segue o seu próprio entendimento.

Ao tratar da igualdade ${ }^{3}$ de instrução, ele defende que seja proporcionada "aquela que exclui toda dependência, ou forçada ou voluntária" (CONDORCET, 1993, p. 184). Para o autor, a escola deve formar sujeitos que, ao atingirem a vida adulta, possam agir independentes dos outros, é o ideal de uso livre da razão.

Para Condorcet (1993, p 181), os homens livres são aqueles "que só reconhecem a razão como seu senhor" (CONDORCET, 1993, p. 181). É a supremacia da razão sobre qualquer outro poder, tudo deveria passar pelo seu crivo. No entanto, essa liberdade não é somente em relação aos outros cidadãos, mas também se refere às instituições políticas e religiosas. Segundo Souza (2008, p.11),

Para Condorcet, o sistema de instrução pública deve ser inteiramente independente dos poderes religiosos, mas também dos poderes públicos. O caráter laico do ensino público não deve ser entendido apenas como independência em relação às religiões, mas também como independência em relação aos poderes políticos constituídos.

Assim, o ideal de liberdade de consciência de Condorcet está intimamente relacionado com sua defesa da escola pública e laica. A escola pública, compreendida como financiada pelo Estado, mas não controlada por ele, não podendo ser usada como aparelho ideológico de Estado, "o poder público não pode nem mesmo, em nenhum assunto, ter o direito de mandar ensinar opiniões como se fossem verdades" (CONDORCET, 2008, p. 47). Os governantes não podem impedir a difusão de novas verdades através da escola e nem de teorias que são contrárias aos interesses de certos grupos políticos, "enfim, nenhum poder público deve ter nem autoridade nem mesmo crédito para impedir o desenvolvimento de novas verdades e o ensino das teorias contrárias à política particular ou aos interesses momentâneos" (CONDORCET, 2010, p. 23-25).

Para o autor, inclusive, a constituição do país não pode ser ensinada como dogma, "se lhes dizemos: eis o que deveis adorar e crer, então se trata de uma religião política que se quer criar, uma cadeia preparada para os espíritos, e viola-se a liberdade em seus direitos mais sagrados" (CONDORCET, 2008, p.53). Pode-se observar que é proibido ensiná-la como crença para não ferir a liberdade de consciência.

Para o autor o estudo da Constituição do país deve integrar os conteúdos ensinados na escola com o objetivo de explicar o seu teor, para que cada geração possa julgá-la e corrigi-la, se necessário. É a defesa do sujeito ativo que participa no melhoramento da sociedade em que vive.

Condorcet divide o ensino em cinco graus de instrução com as seguintes designações " $1{ }^{\circ}$ Escolas primárias; $2^{\circ}$ Escolas secundárias; $3^{\circ}$ Institutos; $4^{\circ}$ Liceus; $5^{\circ}$ 
Sociedade nacional das ciências e artes" (CONDORCET, 2010, p. 25). As instituições escolares ficariam sob o controle da Sociedade nacional das ciências e das artes, "instituída para fiscalizar e dirigir os estabelecimentos de instrução, para ocupar-se do aperfeiçoamento das ciências e das artes, para recolher, encorajar, aplicar e difundir as descobertas úteis" (CONDORCET, 2010, p. 34).

Com relação à inspeção dos estabelecimentos escolares, há uma divisão de responsabilidades, onde cada grau de instrução seria controlado pelo grau imediatamente superior. Segundo Boto (1996, p. 141) “o Estado ficaria, pois, sem qualquer dispositivo para agenciar as instituições educativas, que, por sua vez, constituiriam praticamente uma rede auto-administrativa".

Para compreender como se evitaria o controle do Estado na escola pública, será apresentado como ocorreria o processo de escolha dos professores do ensino primário e secundário, previsto no Relatório e Projeto de Decreto Sobre a Organização Geral da Instrução Pública de 1792. Os professores dos institutos do distrito fariam uma lista dos elegíveis para o ensino primário e o secundário. O primário seria escolhido pela "asamblea de padres de familia del distrito en que se encuentre la escuela" e o secundário pelo "cuerpo municipal del lugar en que se halle situada la escuela" (CONDORCET, 1997, p. 282).

A preocupação da divisão da responsabilidade da instrução já aparecia nas memórias escritas em 1791, que é a base do Relatório e Projeto de Decreto de 1792 e que defendia três fases separadas para escolher os professores, "é sempre mais difícil agir por intriga em três julgamentos separados, se eles não forem feitos pelas mesmas pessoas" (CONDORCET, 2008, p. 126).

O que o autor deseja é colocar outros mecanismos de controle para evitar ou dificultar favorecimentos, imposição de interesses de certos grupos ou de governantes. $\mathrm{O}$ que se observa é a divisão do poder, havendo vários segmentos compartilhando a construção e o controle da escola. Todos têm certo controle sobre a instrução, mas também são controlados, nenhum concentra ou monopoliza o governo da escola. Assim, o uso da escola como aparelho ideológico de estado é uma negação dos princípios de Condorcet.

Condorcet (2008, p. 47) também é contra a presença de qualquer conteúdo religioso na escola pública, "as opiniões religiosas não podem fazer parte da instrução comum”, para não ferir a liberdade de consciência.

Em relação à moral, o autor compreende ser ela independente dos dogmas religiosos, pois "não é preciso ligar a instrução da moral às ideias gerais de religião" (CONDORCET, 2010, p. 31).

Os assuntos religiosos devem estar fora das questões de Estado, ficando o cidadão livre para escolher e exercer qualquer culto que desejar seguir. O ensino religioso "deve ser ensinado nos templos, por seus ministros" (CONDORCET, 2010, p. 30). Por escola laica, o autor entende a ausência total da religião. Assim, não havendo ensino religioso na escola pública, o pai, independente de qualquer religião que professa, pode mandar seu filho à escola e não terá sua liberdade de consciência desrespeitada. "E o poder público não terá usurpado os direitos de consciência sob pretexto de esclarecê-la e de conduzi-la" (CONDORCET, 2008, p. 30). Observa-se a relação entre a ausência da religião no espaço escolar e a defesa da liberdade de consciência.

Pode-se concluir que, para Condorcet, cabe à instrução primária capacitar o sujeito a fazer o uso da sua própria razão, não se submetendo, em suas ações, a nenhuma pessoa ou instituições políticas e religiosas, ou seja, é o ideal de liberdade de consciência. Assim, a sua defesa da liberdade de consciência tem implicação em sua concepção de escola pública e laica. A escola pública é compreendida como financiada pelo Estado, mas não 
controlada por ele, enquanto a escola laica é entendida como a ausência total dos ensinamentos religiosos na escola.

A partir deste momento será analisado o livro de Humboldt (1990) intitulado "Os limites da acção do estado". Devido a sua preocupação em não restringir a liberdade de consciência, ele delimita a ação do Estado em manter a segurança frente ao inimigo externo e garantir que cada cidadão não interfira no direito do outro, pois "a garantia da segurança, tanto frente ao inimigo exterior, como frente às tensões interiores, deve constituir o fim do Estado e o objeto da sua atividade" (HUMBOLDT, 1990, p. 48).

Humboldt (1990, p. 48) considera que "sem segurança não há liberdade", pois é a garantia que o outro não vai invadir o seu direito, que possibilita ao cidadão desenvolver plenamente as suas potencialidades. Essa concepção do autor está imbricada com o seu objetivo de formação do homem total, não parcial e limitado. E essa formação só é possível em um ambiente de liberdade, "o verdadeiro fim do homem é a mais elevada e proporcionada formação possível das suas forças como um todo. E para esta formação, a condição primordial e inescusável é a liberdade" (HUMBOLDT, 1990, p. 19).

Devido a sua defesa do desenvolvimento pleno do homem, ele é contra a educação pública, "quer dizer organizada ou dirigida pelo Estado", por considerar que o importante é "a formação do homem dentro da mais elevada variedade; e a educação pública, mesmo quando evitasse este defeito e se limitasse a nomear e a manter os educadores, favoreceria sempre uma forma determinada" (HUMBOLDT, 1990, p. 59).

Pode-se observar que o autor é contra a concepção de escola pública de Condorcet (2008), que defendia que o Estado deveria financiá-la, mas não controlá-la. Para Humboldt (1990), mesmo restringindo as funções do Estado, na escola pública ele imprimiria uma concepção determinada e conforme o interesse da classe que o controla.

A educação pública, para ele, fere a liberdade de consciência, pois "toda a educação pública imprime ao homem uma certa forma política, posto que nela prevalece sempre o espírito do Governo" (HUMBOLDT, 1990, p. 60). Pode-se observar que o autor considera que na escola pública prevalece a concepção política dos que controlam o governo do Estado, não possibilitando o desenvolvimento livre da razão.

O autor é contra a escola pública por considerar que todas as instituições estatais se propõem a uniformizar a sociedade e o que ele deseja é a diversidade. Conforme Humboldt (1990, p. 27),

Quanto mais o Estado intervém, maior será a semelhança, não só dos meios com que atua, mas também de tudo o que é realizado. E isto é, precisamente, o que os Estados se propõem. Querem o bem-estar e a tranqüilidade. E conseguem ambos, na medida em que os indivíduos lutem menos entre si. Mas ao que o homem aspira, e tem necessariamente de aspirar, é algo muito diferente: é a variedade e à atividade.

Humboldt (1990) é contra a uniformidade da educação pública porque essa elimina a energia do sujeito em detrimento da harmonia, enquanto "o cultivo de determinados aspectos vivendo nas situações e relações mais diversas - que é o natural da educação privada - produz aquela harmonia e sem sacrifício da energia" (HUMBOLDT, 1990, p. 61).

Pode-se constatar que Humboldt considera que a educação pública, através da uniformidade, busca a harmonia eliminando a energia do sujeito, enquanto a educação privada, devido à diversidade, também alcança a harmonia, mas mantém o vigor do sujeito e, assim, possibilita desenvolver plenamente as suas potencialidades.

Apesar do autor fazer várias referências a Mirabeau, muito do que ele defende da escola privada já estava presente em Adam Smith (1996), como na seguinte passagem, 
"entre homens livres surge a emulação e os educadores são melhores porque a sua sorte depende do êxito do seu trabalho e não da promoção esperada do Estado" (HUMBOLDT, 1990, p. 61). Essa concepção de que a emulação, a disputa entre os homens livres e entre os professores levaria a um melhor desempenho dos professores privados e que o professor público, que recebe o seu salário independente da qualidade de seu serviço, é caracterizado como desleixado, já estava presente em Adam Smith (1996, p. 246) "se o professor fosse pago totalmente, ou mesmo principalmente, com o dinheiro do Estado, logo começaria a negligenciar seu trabalho". Seguindo nesse mesmo sentido, Say (1983, p. 408) afirma que,

Um professor ou uma instituição privada não receberão salários adequados num país onde se podem encontrar gratuitamente professores e um ensino similar, ainda que mais medíocres. Sacrificar-se-á o melhor ao pior, sufocando-se, ao mesmo tempo, os esforços privados, origem de tantos benefícios em economia pública.

Essas passagens de Smith (1996) e de Say (1983) servem para demonstrar que esse é um tema da época e não é a visão exclusiva de Humboldt, mas, por outro lado, entrava em contraste com outras visões, como a de Condorcet (2008), que apesar de defender a liberdade de consciência, defende também a escola pública de uma forma bem peculiar.

Para finalizar a sua postura contrária à intervenção do Estado na educação, ele afirma "parece-me que a educação pública está totalmente fora dos limites dentro dos quais deve o Estado manter a sua atuação" (HUMBOLDT, 1990, p. 62).

No que se refere à religião, Humboldt (1990, p. 64) considera ser um campo em que o Estado não deve intervir, devendo dar total liberdade, pois qualquer ingerência se constitui em restrição da liberdade, "não posso imaginar que haja alguma forma de intervenção nesse terreno, que não se traduza, de certa maneira, numa canalização, numa restrição da liberdade dos indivíduos".

Para o autor, não é obrigatório ensinar os princípios morais atrelados aos pressupostos religiosos. Conforme Humboldt (1990, p. 68), "a moralidade, mesmo tratando-se das suas consequências mais profundas para o homem, não depende, em absoluto, da religião, nem tem porque ir necessariamente unida a ela".

Isso não quer dizer que o autor seja contra a relação entre princípios morais e religião, mas ele é contra a compreensão de que essa seja a única forma de se adquirir pressupostos morais ou que se imponham dogmas religiosos para moralizar o sujeito. $\mathrm{O}$ importante é que os princípios morais ou religiosos sejam adquiridos pelo ser humano sem imposição, esses "só resultariam eficaz na medida em que procedera da conjunção de todas as ideias e de todos os sentimentos, em que nascera por si mesmo, mais do interior da alma que incrustado por fora" (HUMBOLDT, 1990, p. 72).

A apropriação dos pressupostos religiosos depende das peculiaridades de cada sujeito, pois, "o modo como nasce a religião espontaneamente num homem e como a aceita, depende por completo da sua forma geral de ser, pensar e sentir" (HUMBOLDT, 1990, p. 78). Assim, se ele segue uma religião por sua livre escolha, não há restrição à liberdade.

O autor defende a liberdade de consciência para todos, inclusive para os mais humildes. Conforme Humboldt (1990, p. 77),

Ninguém acredita tão-pouco que essa liberdade de espírito e de ilustração são só algo para uns poucos dos membros do povo e que são inúteis ou, inclusivamente, contraproducentes, para a grande maioria, cuja preocupação se esgota em satisfazer as necessidades materiais da vida; 
não se creia que só pode influir nessa maioria mediante a propagação de determinados princípios, mediante a restrição da liberdade de pensamento.

Humboldt $(1990,79)$ finaliza sua exposição sobre a religião afirmando que tudo "aquilo que tem que ver com a religião encontra-se fora do âmbito de atuação do Estado e que tanto os pregadores como o culto em geral são instituições das comunidades que devem ficar à margem do controle especial por parte do Estado".

Por fim, deve-se destacar que Humboldt (1990) é um defensor da liberdade de consciência a todos os integrantes da sociedade. Para o autor, não cabe ao Estado intervir na escola, pois esse sempre defende determinados pressupostos que são dos integrantes do governo e, assim agindo, fere a liberdade de consciência. Essa intervenção busca uniformizar a sociedade, com o que o autor também não concorda, pois o ideal é a variedade para o homem poder desenvolver plenamente as suas potencialidades. A religião é outro campo que não cabe ao Estado intervir, pois qualquer ingerência nesse campo acarreta na defesa de certa concepção religiosa, contrariando a liberdade de consciência. $\mathrm{O}$ ideal é que o sujeito, livremente, através de suas características, escolha ou não seguir alguma religião.

O último autor que será analisado é John Stuart Mill, usando como referência as suas obras "Princípios de economia política" e "Sobre a liberdade", publicadas em 1848 e 1859 , respectivamente.

$\mathrm{Na}$ introdução de "Sobre a liberdade", o autor delimita o tema a ser tratado, "o assunto desse ensaio não é a chamada liberdade do querer, [...], é sim a liberdade civil ou social: a natureza e os limites do poder que a sociedade legitimamente exerce sobre os indivíduos" (MILL, 1991, p. 45). Esse poder legítimo, da sociedade sobre o cidadão, se restringe unicamente aos atos que trazem danos a outrem. Conforme o autor,

O único propósito com o qual se legitima o exercício do poder sobre algum membro de uma comunidade civilizada contra a sua vontade é impedir dano a outrem [...] Para justificar a coação ou a penalidade, fazse mister que a conduta de que se quer desviá-lo tenha em mira causar dano a outrem. A única parte da conduta por que alguém responde perante a sociedade é a parte que concerne aos outros. Na parte que diz respeito unicamente a ele próprio, a sua independência é, de direito, absoluta. Sobre si mesmo, sobre o seu próprio corpo e espírito, o individuo é soberano. (MILL, 1991, p. 53).

Pode-se observar que em relação aos atos que são intimamente ligados ao próprio sujeito, ele tem total liberdade. As outras pessoas podem aconselhá-lo, tentar persuadi-lo a não ter tal conduta, mas não podem oprimir a sua liberdade individual. Por outro lado, as pessoas não são obrigadas a terem como companhia, outras que não lhes agradem, "temos o direito de evitá-lo (embora não o de ostentar esse evitamento), porque temos o direito de escolher a companhia que nos é mais agradável" (MILL, 1991, p. 120).

A sociedade pode legalmente restringir a liberdade individual nos atos que trazem danos a outrem. Para usar esse poder, não basta que o dano seja determinado por opiniões divergentes, ele deve trazer danos materiais ao outro. A diversidade de opiniões não pode ser o critério para intervir no direito do outro, pois "o gosto de uma pessoa é tanto do seu peculiar interesse como a sua opinião" (MILL, 1991, p. 126).

Entre as várias liberdades que o autor trata está a de consciência, que ele define por "liberdade de pensar e de sentir, liberdade absoluta de opinião e de sentimento sobre 
quaisquer assuntos, práticos ou especulativos, científicos, morais ou teológicos" (MILL, 1991, p. 56). Essa liberdade de consciência não se restringe ao direito de pensar, mas "da qual são inseparáveis as liberdades cognatas, de falar e escrever" (MILL, 1991, p.58) ${ }^{4}$. É a liberdade de consciência na sua forma irrestrita.

Esta defesa do uso público da razão se insere na sua concepção de que é necessário confrontar as ideias, pois é na contradição que a sociedade avança. Para o autor, não basta a experiência, é preciso a discussão, o ser humano "é capaz de retificar os seus enganos pela discussão e pela experiência. Não pela experiência apenas. Deve haver discussão, para mostrar como se há de interpretar a experiência" (MILL, 1991, p. 63). Para ampliar o conhecimento é preciso ouvir o contrário, o conhecimento se constrói na relação com o outro, pois "os homens não são infalíveis; que as suas verdades, pela mor parte, são meias verdades" (MILL, 1991, p. 98). Devido a essa concepção da meia verdade é que se precisa ouvir o outro para avançar, pois a outra parte da verdade pode estar com o outro, ou melhor, se o debate for amplo, pode cada um ter uma parcela da verdade e, assim, as partes se completam. Segundo o autor,

mesmo que a opinião a que se impôs silêncio seja um erro, pode conter, e muito comumente contém, uma parte de verdade. E, uma vez que a opinião geral ou dominante sobre um assunto é raramente, ou nunca, a verdade inteira, só pela colisão das opiniões contrárias se faz provável se complete a verdade com a parte ausente (MILL, 1991, p. 94).

Seguindo no mesmo sentido, o autor não quer a padronização dos seres humanos, que se construam modelos de homens e de sociedades. Ele quer é a pluralidade, pois o desenvolvimento da humanidade se dá pela sua diversidade. Ao uniformizá-la, está diminuindo a sua possibilidade de progresso, pois é na pluralidade que a sociedade avança. Inclusive ele destaca que o progresso europeu se deve aos diversos caminhos empregados para consegui-lo e que "já começa, porém, a usufruir esse benefício num grau consideravelmente menor. Ela está decididamente avançando para o ideal chinês da uniformidade" (MILL, 1991, p. 114).

Essa constatação do autor, de que a Europa de seu tempo estava se uniformizando e que isso era prejudicial ao seu desenvolvimento, vem a ser importante para o presente artigo por demonstrar a contradição no uso dessas ideias pela sociedade, que tem a burguesia como classe hegemônica.

No capítulo XI, do livro quinto, do volume III, da obra "Princípios de economia política", que é anterior ao livro "Sobre a liberdade", Mill (1988) trata dos fundamentos e dos limites do laisser-faire, onde também defende que o sujeito tem total liberdade em tudo que diz respeito a si, desde que não afete os interesses dos outros.

Para o autor, a regra geral deve ser a interferência mínima do Estado, por considerar que as pessoas são as melhores julgadoras de seus próprios interesses, "em suma, o laisserfaire deve ser a prática geral; qualquer desvio dessa prática é um mal certo, a menos que isso seja exigido em função de algum bem ingente" (MILL, 1988, p. 257). Entre os casos que podem demandar a interferência do Estado está a educação elementar.

A suposição de que o consumidor é o melhor árbitro sobre a mercadoria, deve ser admitida com ressalva. Entre as exceções está a capacidade das pessoas incultas serem os juízes da necessidade da educação. Esses sujeitos são os que mais necessitam de instrução e, geralmente, são os que menos a querem. Devido a uma grande parcela da sociedade não ter o desejo de se instruir, o mercado não será eficiente, assim, a educação "é uma dessas coisas que é admissível, em princípio, ao governo ter que proporcionar ao povo" (MILL, 
1988. p. 260). Deve-se destacar que o povo, a que o autor se refere, é a população pobre, a quem o Estado deve providenciar a educação.

Mill (1988, p. 261) considera legítimo ao Estado tornar o ensino elementar obrigatório, devendo, no entanto, adotar medidas que possibilitem o acesso das crianças pobres à escola. Portanto, defende que a educação seja gratuita ou que o valor a ser pago seja insignificante. Quanto à censura ao Estado financiar a educação dos pobres, sob o argumento de que isto enfraqueceria a capacidade de iniciativa do aluno, tornando-o dependente, o autor responde que isto não ocorreria se a instrução disponibilizada cumprir o seu verdadeiro papel de desenvolver as faculdades ativas do aluno, tornando-o independente. Desta forma "é ajuda para daí em diante se poder agir sem necessidade de ajuda" (MILL, 1988, p. 261).

O autor considera que na Inglaterra e na maior parte da Europa de seu tempo, a classe trabalhadora não qualificada não dispunha de recursos financeiros para investir na instrução escolar de seus filhos. Na Inglaterra a instrução proporcionada pela escola, financiada pela contribuição voluntária dos cidadãos, era quantitativamente insuficiente e qualitativamente péssima. Assim, de acordo com o autor, seria dever do Estado dar "apoio financeiro às escolas primárias, para torná-las acessíveis a todos os filhos de pais pobres, não pagando os pais nada, ou então uma quantia irrisória" (MILL, 1988, p. 261).

Pode-se observar que o autor não aponta que o Estado deva criar escolas, mas disponibilizar recursos às escolas privadas para atenderem também os alunos pobres. No entanto, posteriormente, o autor faz alusão de que, em certos casos, é dever do Estado criar escolas, desde que não constitua monopólio em qualquer nível educacional que forneça. $\mathrm{O}$ Estado não deve dar privilégios aos seus professores e aos alunos formados em suas escolas, inclusive, deve dar preferência aos professores privados. Para o autor, o governo não deve controlar totalmente a educação de seus cidadãos devido a possibilidade do uso da escola como elemento de controle da população, ferindo assim, a liberdade de consciência. Conforme Mill (1988, p. 261),

Não é tolerável que um governo, de direito ou de fato, tenha controle total sobre a educação do povo. Possuir tal controle e exercê-lo efetivamente é despotismo. Um governo que puder moldar as opiniões e os sentimentos do povo, desde a adolescência, pode fazer com eles o que bem entender. Ainda que, portanto, o governo possa, e em muitos casos deva criar escolas e colégios, não deve nem obrigar nem aliciar ninguém a freqüentá-los; tampouco é admissível fazer depender em qualquer grau de autorização governamental o direito de os indivíduos criarem estabelecimentos de ensino que concorram com os do Estado. Seria justificável exigir de todos que tenham instrução em certas coisas, mas não prescrever como e de quem devem obtê-la.

A preferência do autor é pela escola privada, mas em determinado estágio de desenvolvimento social, ele aceita que a mesma seja fundada pelo Estado. Nos países em que a população é muito pobre, ou pouco desenvolvida intelectualmente, não existirá portos, estradas, hospitais e escolas se o Estado não os criarem. Esta intervenção deve ser entendida como transitória, pois a sua influência deve ser de tal "forma que não tenda a fazer aumentar e perpetuar esta incapacidade, mas de corrigi-la" (MILL, 1988, p. 276). O Estado deve incentivar a iniciativa particular, "seus recursos pecuniários serão aplicados, quando for exeqüível, em ajudar os esforços privados, mais do que substituí-los" (MILL, 1988, p. 276). 
O livro "Sobre a liberdade" defende que o Estado deveria obrigar os pais a educarem os filhos, cabendo a esses escolherem onde educá-los, ficando o Estado com a responsabilidade de pagar o ensino para os que não tenham condições. Segundo Mill (1991, p. 149).

Se o governo se resolvesse a exigir para cada criança uma boa educação, poderia poupar-se ao incômodo de a providenciar. Poderia deixar aos pais obter a educação onde e como lhes agradasse, e contentar-se com auxiliar o pagamento das despesas de escola das crianças mais pobres, custeando as despesas totais das que não tenham quem por elas pague. As fundadas objeções que se fazem à educação pelo Estado não se aplicam à imposição pelo Estado da obrigação de educar, mas ao fato de assumir o Estado a direção dessa educação - o que é coisa inteiramente diferente.

Percebe-se que a ideia defendida pelo autor é de que o Estado deve custear, na rede privada, parte da educação dos pobres e totalmente a dos órfãos. No entanto, Mill (1991) é contra o Estado ter o mando da educação, por compreender que o ensino direcionado por este tende a moldar a sociedade conforme os ditames da classe dominante e o que ele almeja é a diversidade na sociedade e na educação. O autor é contra o uso da escola como aparelho ideológico de estado. Conforme Mill (1991, p. 149),

eu estou tão longe como qualquer outro de pleitear fique a educação do povo, no todo ou em grande parte, nas mãos do Estado. Tudo o que se disse da importância da individualidade de caráter, e da diversidade de opiniões e de modo de conduta, envolve, como sendo da mesma indizível importância, a diversidade de educação. Uma educação geral pelo Estado é puro plano para moldar as pessoas de forma exatamente semelhante. E, como o molde em que são plasmadas é o que agrada a força dominante no governo, quer esta um monarca, um clero, uma aristocracia, quer a maioria da geração existente, a educação pelo Estado, na medida em que é eficaz e bem sucedida, estabelece um despotismo sobre o espírito, que, por uma tendência natural, conduz a um despotismo sobre o corpo.

Apesar de ser contra o Estado ter a gerência da educação do povo, posteriormente ele apresenta que pode ocorrer uma educação estabelecida e controlada pelo Estado, empregada como exemplo e estímulo para manter a excelência do ensino. Porém, a escolha dessa escola ou modelo se daria somente após a competição de vários experimentos. Essa intervenção é possível para evitar um mal maior, que é a falta de educação, mas apenas, "quando a sociedade se encontra, em geral, numa situação de tal atraso, que não poderia providenciar ou não providenciaria, por si mesma, quaisquer instituições convenientes de educação" (MILL, 1991, p. 149).

O que se observa é que o autor aceitaria essa intervenção do Estado somente como exceção e com muitas ressalvas, pois ele mesmo contrapõe essa possibilidade ao afirmar que se esses mestres eram qualificados para atender a tarefa da educação da mocidade sob o controle do Estado, também eram capazes de proporcionar uma boa educação, "uma vez garantida a sua paga pela existência de uma lei que tornasse compulsória a educação, combinada com a ajuda do Estado aos incapazes de custear as despesas" (MILL, 1991, p.150).

Conforme exposto nas duas obras, o autor somente aceita que o Estado crie escolas nas sociedades atrasadas, onde a iniciativa privada não as providencia por si. Essa ação governamental deve ser compreendida como exceção e transitória. $\mathrm{O}$ autor prefere que o 
Estado torne o ensino obrigatório e que tal ensino seja custeado na rede privada aos alunos que não tenham condições de pagar.

Primeiramente, para o autor, a obrigatoriedade do ensino não é uma restrição da liberdade porque o ideal de liberdade que cada sujeito tem sobre os seus próprios interesses, "pretende aplicar-se somente aos seres humanos de faculdades maduras. Não nos referimos às crianças ou aos jovens abaixo da idade fixada pela lei para a emancipação masculina ou feminina" (MILL, 1991, p. 54). E, em segundo lugar, os pais não têm o direito de não instruir os filhos, pois esse é um dever com a criança e com a sociedade.

A lei que tornava o ensino elementar obrigatório para todas as crianças, seria cumprida não pela oferta de escolas pelo Estado, mas através de exames públicos "extensivos a todas as crianças, desde tenros anos. Poder-se-ia fixar uma unidade na qual toda criança devesse sujeitar-se a exame que averiguasse se ele, ou ela, sabe ler" (MILL, 1991, p. 150).

Pode-se observar que, através do emprego de "ele" e "ela", o ensino obrigatório e universal atingiria também as meninas. Essa defesa está de acordo com a sua concepção de expandir os mesmos direitos dos homens para as mulheres, pois, "nada é mais necessário para o completo removimento do mal do que gozarem as mulheres dos mesmos direitos, e deverem receber a proteção da lei da mesma maneira, que todas as outras pessoas" (MILL, 1991, p. 148).

Em relação às crianças reprovadas no exame, se comprovada a negligência do pai, este poderia ser punido com multa, "a ser satisfeita, se necessário, por trabalho e a criança posta em escola às suas expensas" (MILL, 1991, p. 150). O exame seria a forma empregada para forçar os pais a cumprirem a lei da obrigatoriedade do ensino.

Apesar do autor, inicialmente, ter se referido à leitura, ele defende que no decorrer dos anos de estudos do aluno, "o exame seria renovado, com uma série de matérias gradualmente ampliada" (MILL, 1991, p. 150). Essa expansão visa garantir a universal aquisição de um mínimo de conhecimento geral, no entanto, ele não especifica o que seria esse conhecimento mínimo geral. Para além desse mínimo, os exames seriam facultativos.

Para evitar que o Estado influenciasse na obtenção do conhecimento e impusesse a sua concepção à sociedade, ponto de vista que pertence à classe dominante, o conhecimento exigido para passar nos exames, se limitaria, "a fatos e a ciência positiva" (MILL, 1991, p. 150). Essa abordagem do autor está em conformidade com a sua época, em que se concebia que certos conhecimentos não variavam para um religioso ou um ateu, para um inglês ou um americano do norte, como por exemplo, a língua, os fatos ou os cálculos.

Por outro lado, os exames dos conteúdos controversos, como religião, política ou filosofia, não deveriam versar sobre a verdade ou a falsidade destes, mas sobre os seus fundamentos. O que interessa verificar é se o examinado está em conformidade com os pressupostos do autor analisado ou com os dogmas da religião que versa, sem necessariamente obrigá-lo a concordar com eles. Conforme Mill (1991, p. 150),

um estudante de filosofia estaria nas melhores condições para sofrer um exame sobre Locke e sobre Kant, quer siga um, quer siga outro, quer não siga nenhum dos dois; e não há objeção razoável a que se examine um ateu sobre as provas do Cristianismo, desde que se não exija dele que nelas acredite.

Para o autor, conhecer os contrários faz parte do caminho necessário para ampliar o conhecimento, pois, conforme exposto anteriormente, cada parte de uma disputa está com 
meia verdade. Ao governo interessa que o cidadão seja instruído e não que siga dogmas religiosos ou filosóficos.

Havia a possibilidade dos alunos "obterem o ensino de religião, se os pais o quisessem, nas mesmas escolas em que lhes ensinam outras coisas" (MIIL, 1991, p.150). Esse é um tema que fica a critério dos pais decidirem se querem ou não instruir os filhos sobre religião, e não ao Estado impor a obrigatoriedade. Existem indicativos que permitem afirmar que o ensino de religião não é necessariamente o ensino de uma religião específica, pode ser o ensino dos pressupostos de cada uma das religiões existentes, sem a necessidade de que o aluno acredite em uma delas.

O autor é contra a imposição de verdades pelo Estado, pois "todas as tentativas do Estado para influir nas conclusões dos seus cidadãos sobre matérias debatidas são um mal" (MILL, 1991, p. 150).

Para finalizar a abordagem sobre Mill (1991), pode-se concluir que o autor é um defensor da liberdade de consciência, compreendida como a liberdade de pensar, de conhecer, de falar e de escrever e que a liberdade só pode ser restringida se trouxer dano a outrem. Também defende a obrigatoriedade do ensino mínimo a todas as crianças, sendo este fiscalizado pelo Estado através dos exames periódicos e que os pais devem escolher e pagar a escola dos filhos na rede privada de ensino, cabendo ao Estado custeá-la em parte ou totalmente para as crianças pobres e criar escolas somente nas sociedades pouco desenvolvidas, onde a iniciativa privada não o faria. $\mathrm{O}$ autor defende a escola privada e é contra o Estado controlar o ensino, pois esse tende sempre a uniformizar os cidadãos, conforme os interesses da classe dominante. Mill (1991) é um defensor da diversidade na sociedade e no ensino. Com relação ao ensino religioso, o autor defende que a escolha de receber ou não estes ensinamentos cabe aos pais, podendo o aluno, inclusive, aprender os fundamentos de qualquer religião, desde que não seja obrigado a crer neles.

Finalizada a análise dos autores liberais escolhidos para embasar a compreensão do que seja a liberdade de consciência para o liberalismo e a sua implicação na concepção educacional de Condorcet, Humboldt e Mill, se faz necessário defini-la e, posteriormente, concluir a sua implicação em cada um deles. Assim, a liberdade de consciência é a capacidade que o homem esclarecido tem de fazer uso livre da razão, ou seja, é a capacidade de seguir somente a sua razão em suas escolhas, não se submetendo a outro sujeito ou instituição. A liberdade de consciência não se restringe somente a pensar, mas também a conhecer, falar e escrever. É, também, o direito de fazer livremente o uso público da razão. Outro elemento importante é que o esclarecimento não é para poucos, mas para todos e que a humanidade somente estará esclarecida quando todos assim estiverem.

Pode-se concluir que a liberdade de consciência influenciou de forma diferente a concepção de escola pública e laica em cada autor. Condorcet compreende a escola pública como financiada pelo Estado, mas não controlada por ele e a escola laica é a ausência da religião no espaço escolar. Humboldt considera que, tanto a escola quanto a religião, devem estar fora da intervenção do Estado, sendo contra a escola pública. $\mathrm{O}$ autor defende também que o ensino da moral não deve estar obrigatoriamente atrelado a pressupostos religiosos, cabendo ao sujeito livremente seguir ou não uma religião. Para Mill, o Estado deve pagar parte ou totalmente a escola dos pobres, mas não controlá-la. Ele defende a escola privada, mas aceita a escola pública, como exceção e de forma transitória, nas sociedades pouco desenvolvidas. Para o autor, cabe ao Estado fiscalizar, através de exames, se os pais estão cumprindo a obrigatoriedade de ensino aos filhos. A escolha se o aluno deve receber ou não o ensino religioso cabe aos pais e, inclusive, o aluno pode aprender os dogmas de qualquer religião desde que não seja obrigado a crer neles. 


\section{Palavras finais}

Apesar de ter apresentado na introdução que o liberalismo se deduz inteiro a partir do ideal de liberdade de consciência e que, para ele, a liberdade é o bem supremo, deve-se destacar que essas são concepções de dois autores ${ }^{5}$ que defendem o liberalismo. Para o Marxismo, a propriedade privada e as relações econômicas são o bem supremo do liberalismo. Nesta perspectiva a compreensão do liberalismo não tem a liberdade de consciência como seu componente essencial, pois ao longo da história, por necessidades do capital, esta liberdade foi, por várias vezes, restringida pelos próprios defensores do liberalismo.

Com relação a intervenção do Estado na instrução, considerada pelos liberais, aqui analisados, como uma restrição à liberdade de consciência do cidadão, o que se observa é que alguns liberais, como Mill, fecham as portas para essa interferência, mas através das exceções, abrem as janelas. Assim, quando o capital necessita da intervenção do Estado, os liberais se dissimulam através do discurso da necessidade do bem público e permitem que o Estado atue em seu benefício.

As explicações do predomínio de uma concepção ideológica não devem ser buscadas nas ideias, mas na prática material. Conforme Marx e Engels (1986, p. 56) "não se explica a práxis a partir da ideia, mas se explica as formações ideológicas a partir da práxis material".

Dessa forma, a partir da compreensão do momento histórico vivido pelos autores analisados, se buscará explicar a defesa da liberdade de consciência e a sua influência nas concepções de escola pública ou privada e laica.

A burguesia em ascensão na Europa tinha como principais entraves ao desenvolvimento do modo de produção capitalista e a sua afirmação como classe dominante, a nobreza e o clero, que não pagavam impostos e monopolizavam o ingresso aos cargos públicos das instâncias superiores do Estado. Assim, as revoluções burguesas aboliram "os privilégios estamentais da nobreza e do clero" (GORENDER, 1982, p. 17).

Apesar de as revoluções burguesas terem abolido tais privilégios, a consolidação da burguesia como classe dominante deve ser entendida como processo. Pode-se afirmar que durante o período ${ }^{6}$ analisado nesse artigo, a burguesia busca se firmar como classe dominante e, como tal, solidificar seu domínio no Estado. Durante esse processo é preciso atacar a nobreza e o clero, por isso a defesa do ensino ser independente do Estado e da Igreja, para o cidadão ter a liberdade de consciência.

Ao se consolidar como classe hegemônica, a burguesia tende a uniformizar todos os espaços da sociedade em conformidade com os seus interesses e a sua concepção de mundo. Inclusive, Mill (1991) já identificava que a sociedade européia de seu tempo seguia no sentido contrário de sua defesa da diversidade e da pluralidade. A burguesia, que antes das revoluções burguesas era revolucionária, passa a ser conservadora. Assim, quando a burguesia se consolida como classe dominante e tem o Estado ao seu serviço, a escola passa a ser o Aparelho Ideológico de Estado dominante. Althusser (1974, p. 60) considera que o Aparelho Ideológico de Estado "que foi colocado em posição dominante nas formações capitalistas maduras, após uma violenta luta de classes políticas e ideológicas contra o antigo Aparelho Ideológico de Estado dominante ${ }^{7}$, é o Aparelho Ideológico Escolar".

A classe que domina o modo de produção numa época é a classe que tem as ideias dominantes. Conforme Marx e Engels (1986, p. 72) "as ideias da classe dominante são, em cada época, as ideias dominantes". Essa dominação se encontra em todos os espaços, 
dominando como pensadores e produtores de ideias, além de regularem "a produção e a distribuição das ideias de seu tempo".

A escola é um dos espaços que a classe dominante controla para distribuir as suas ideias, pois a criança, ao chegar à escola, já está impregnada pelas concepções de mundo da classe dominante. Segundo Ponce (1996, p. 180), enquanto os professores "crêem que recebem em suas mãos a alma virgem das crianças, a burguesia já lhes ensinou às escondidas tudo o que ela quer que sintam e acreditem".

Deve-se reconhecer, por um lado, que a escola é um importante Aparelho Ideológico de Estado que a classe dominante usa para legitimar a sua posição dominante e reproduzir a estrutura de classe. Por outro lado, não se pode deixar de reconhecer que ela apresenta contradições que são determinadas pela correlação de forças de uma dada sociedade. Assim, apesar de reconhecer a escola como espaço de reprodução da estrutura de classe e da posição dominante da classe dominante, ela também deve ser pensada como um campo de luta. Segundo Tambara (1995, p. 41) "se é inquestionável que a educação constitui elemento utilizável pela classe hegemônica para legitimamente usar seu poder sobre os demais, não é menos verdade que pode se constituir em objeto destinado a minar o poder constituído". No mesmo sentido, Althusser (1974, p. 49) afirma que "os Aparelhos Ideológicos de Estado podem ser não só o alvo, mas também o local da luta de classes".

A possibilidade dessa luta será determinada pela capacidade ou incapacidade da classe dominante de reproduzir a sua concepção de mundo e, também, "isto depende da peculiar correlação de forças decorrente de um específico estágio de desenvolvimento das forças produtivas e da especificidade das relações sociais" (TAMBARA, 2000, p. 28 - 29).

Apesar de reconhecer a escola como um dos locais da luta de classe e de combater o predomínio da ideologia dominante, é fundamental complementar essa assertiva afirmando que a burguesia sempre esconde o caráter de classe no interior da escola. Conforme Saviani (2008, p. 230), "a função de mascarar os objetivos reais por meio de objetivos proclamados é exatamente a marca distintiva da ideologia liberal".

Assim, a análise pautada pelo materialismo histórico deve desnudar as aparências do liberalismo. Por outro lado, não basta revelar o que o liberalismo mascara, é preciso expor com o intuito de preparar para a ação. Ação entendida como superação do capital.

Com relação à escola laica, pode-se afirmar que ela está relacionada com a defesa do Estado laico, que tem por objetivo eliminar o poder de qualquer religião no Estado, quando essa se comporta como entrave aos propósitos da burguesia e ao desenvolvimento do capitalismo.

Por outro lado, deve-se destacar que Marx (2009, p. 53) considera o Estado laico um progresso da humanidade, alcançado pela burguesia. No entanto, a emancipação política do Estado da religião não é a consumação da emancipação humana, "é o modo político de alguém se emancipar da religião".

As discussões sobre os limites da intervenção do Estado na instrução e o ensino laico são temas recorrentes na história da educação brasileira, inclusive, na atualidade. Para os pesquisadores que se pautam pelo materialismo histórico a pergunta que devem fazer no presente - século XXI - é se as políticas públicas educacionais hegemônicas no Brasil em nível nacional atendem os interesses da classe trabalhadora ou reforçam os interesses do capital?

Estas palavras finais não pretendem responder a este complexo questionamento, mas indicar possibilidades de respostas. Pode-se afirmar que a análise das políticas públicas em educação, concretizadas em leis, deve levar em conta que elas não são a efetivação do que desejam, na totalidade, os representantes dos liberais (neoliberalismo), mas também não representam, na totalidade, as reivindicações dos segmentos que 
defendem a classe trabalhadora. As políticas educacionais se constroem no jogo político e a sua materialização ocorre como resultado do embate dessas forças em luta.

Com relação ao ensino superior, entre as várias políticas afirmativas do governo federal para expandir o acesso a esse nível de estudos, se destacam o Programa Universidade para Todos (PROUNI) criado pela Lei $\mathrm{n}^{\circ} 11.096$, em 13 de janeiro de 2005, que "visa à concessão de bolsas de estudo integrais e parciais em cursos de graduação e sequenciais de formação específica, em instituições privadas de educação superior" (CASTRO, 2011, p. 32) e o Programa de Apoio a Planos de Reestruturação e Expansão das Universidades Federais Brasileiras (REUNI), criado pelo Decreto ${ }^{\circ} 6.096$, de 24 de abril de 2007, que visa ampliar o acesso e a permanência do aluno no ensino superior público.

A concessão de bolsas de estudos, custeada pelo Estado na rede privada de ensino aos alunos pobres, era defendida por Mill (1988 e 1991), no século XIX, para o ensino elementar. No entanto, na metade do século XX, a concessão de bolsas no ensino superior era defendida pelo autor liberal Friedman (1977, p. 89), que afirma,

qualquer subvenção deve ser passada aos indivíduos, para ser utilizada em instituições de sua própria escolha, com a única condição de que sejam do tipo e natureza convenientes. As escolas governamentais que continuarem em funcionamento deveriam cobrar anuidades que cobrissem os custos educacionais, competindo, assim, em nível de igualdade com as escolas não subvencionadas pelo governo.

Mesmo sem uma análise mais profunda, pode-se afirmar que o PROUNI está mais próximo dos ideais dos defensores do capital e o REUNI, por investir na expansão do setor público, está mais próximo dos interesses da classe trabalhadora. No entanto, o REUNI também representa acréscimo na carga de trabalho docente, ao aumentar a oferta do número de matrículas sem a devida ampliação do quadro de professores, e aumento do trabalho precário, com cursos criados sem as mínimas condições de funcionamento que, além disso, não qualificam como deveriam o aluno. Assim, em certos casos, o REUNI segue a regra brasileira da universalização das políticas sociais, as quais são "acompanhadas por uma queda na qualidade do atendimento" (GOMES e MACIEL, 2012, p. 165).

Apesar de se constatar tais problemas, não se deve esquecer que o REUNI é uma conquista da classe trabalhadora e que precisa continuar lutando pela sua ampliação e aperfeiçoamento. Por outro lado, há uma outra frente de luta que pode ser empregada. A classe trabalhadora poderia utilizar a defesa liberal da concessão de bolsas de estudos pelo Estado, na rede privada, e, através dos sindicatos, associações e outros órgãos que defendem os seus interesses, criar instituições de ensino superior para os trabalhadores. Inclusive, poderia usar o mesmo princípio para os demais graus de instrução.

O objetivo não é abandonar a luta pela escola pública, gratuita e de qualidade, que deve continuar exigindo do Estado um aprofundamento das políticas públicas conforme os interesses do trabalhador. O que se objetiva é abrir uma nova frente de luta para o proletariado.

Para os graus iniciais de estudos, Friedman (1977) defendia que o Estado concedesse uma bolsa de estudos, correspondente ao valor gasto na escola pública, ao aluno que quisesse estudar em uma escola privada. Conforme o autor,

O tipo de solução que parece o mais adequado e justificado por estas considerações - pelo menos para os níveis primário e secundário - seria a combinação de escola pública e privada. Os pais que quiserem mandar os 
filhos para escolas privadas receberiam uma importância igual ao custo estimado de educar uma criança numa escola pública, desde que tal importância fosse utilizada em educação numa escola aprovada (FRIEDMAN, 1977, p. 85).

Pode-se observar que a bolsa de estudo seria usada em uma instituição de ensino aprovada pelo Estado, o que indica um controle no conhecimento a ser difundido. Assim, o Estado controla tanto a escola pública quanto a privada. Para Friedman (1977, p. 79) é impossível manter uma sociedade democrática e estável "sem um grau mínimo de alfabetização e conhecimento por parte da maioria dos cidadãos e sem a ampla aceitação de um conjunto comum de valores. A educação pode contribuir para esses dois objetivos". Pode-se observar que a escola cumpriria a função de incutir valores sociais, que no caso de Friedman (1977), são os princípios do capital.

Como o Estado defende os interesses do capital, e a escola, mesmo sendo um local da luta de classe, é um dos Aparelhos Ideológicos do Estado, a classe trabalhadora deveria usar os recursos provenientes do Estado e exigir que ele nada estabelecesse para as suas escolas. Dessa forma, essa nova frente de luta do proletariado, no campo educacional, também estaria em conformidade com os princípios Marxistas, que segundo Manacorda (2010, p. 359), na ata do Conselho Geral da Associação Internacional dos Trabalhadores de agosto de 1869, consta como sendo de Marx a seguinte intervenção, "a instrução pode ser estatal, sem ficar sob o controle do governo".

Apesar de reconhecer as conquistas do proletariado nas políticas públicas educacionais no Brasil, ao estudar os autores liberais, o que se observa é que elas ainda estão dentro dos limites do liberalismo, ou seja, dentro do que é possível ao capital conceder a classe trabalhadora. No entanto, o uso do termo "conceder" deve ser entendido como conquista alcançada pelo proletário com muita luta e não como um ato benevolente dos defensores do capital.

Por considerar que a escola organizada pelo e para os trabalhadores está fora dos limites do liberalismo, esse novo campo de luta será o mais árduo, porém, poderá trazer as conquistas mais efetivas no campo educacional.

Outro elemento importante para analisar se as políticas públicas estatais, no campo da educação, defendem os interesses da classe trabalhadora ou reforçam os interesses do capital, são os protestos realizados nas ruas em todo o Brasil em 2013, talvez sejam a própria resposta de que essas políticas adotadas pelo governo, não estão dando conta das necessidades da classe trabalhadora, não só na educação, mas também na saúde, segurança, representação política, etc.

Finalizando, nas palavras finais inicialmente buscou-se demonstrar que a relação que havia entre a defesa da liberdade de consciência e o modelo de escola pública ou privada e laica, estava determinada pelos interesses da burguesia. Em um segundo momento, ao refletir sobre as políticas públicas educacionais, no âmbito do governo federal brasileiro, constatou-se que elas não dão conta das necessidades do trabalhador. Assim, fica evidente a necessidade urgente de se repensar, na atualidade, qual deve ser o caminho da luta do proletariado, sem esquecer que o capitalismo é incorrigível e que deve ser superado. 


\section{Referências}

ALTHUSSER, Louis. Ideologia e aparelhos ideológicos do estado, Lisboa: Presença, 1974.

BARROS, Roque Spencer Maciel de. A ilustração brasileira e a ideia de Universidade. São Paulo: EDUSP, 1986.

BOTO. Carlota. A escola do homem novo: entre o iluminismo e a Revolução Francesa. São Paulo: Editora da Universidade Estadual Paulista, 1996.

CASTRO, Alda Maria Duarte Araújo. A expansão e o acesso ao ensino superior: os novos desafios da educação brasileira. In: Luiz de Souza Junior; Magna França; Maria da Salete Barboza de Farias (Orgs.). Políticas de gestão e práticas educativas: a qualidade do ensino. Brasília: Líber Livros, 2011.

CHAVES, Eduardo O. C. O liberalismo na política, economia e sociedade e suas implicações para a educação: uma defesa. In: LOMBARDI, José Claudinei; SANFELICE. José Luis (Orgs.). Liberalismo e educação em debate. Campinas, SP: Autores Associados; HISTEDBR, 2007.

CONDORCET. Esboço de um quadro histórico dos progressos do espírito humano. Trad. Carlos Alberto Ribeiro de Moura. Campinas, S.P: Editora da UNICAMP, 1993.

- Bosquejo de un cuadro histórico de los progresos del espíritu humano y otros textos. Trad. de Francisco González Aramburo. México: Fondo de cultura económica, 1997.

Cinco memórias sobre a instrução pública. Trad. de Maria das Graças de Souza. São Paulo: Editora da Unesp, 2008.

Escritos sobre instrução pública: Condorcet. Trad. de Maria Auxiliadora Cavazzotti e Lígia Regina Klein. Campinas: Autores Associados, 2010.

DALBOSCO, Cláudio A. Kant e a Educação. Belo Horizonte: Autentica Editora, 2011.

FRIEDMAN, Milton. Capitalismo e liberdade. Editora Artenova. 1977.

GOMES, Marco Antônio de Oliveira e MACIEL, Antônio Carlos. O liberalismo e a privatização da educação: a impossibilidade da democracia. In: Revista HISTEDBR Online. Campinas, $\mathrm{n}^{\circ}$ 48, p. 153 - 167, Dez. 2012.

GORENDER, Jacob. A burguesia brasileira. São Paulo: Brasiliense, 1982.

HUMBOLDT, Wilhem Von. Os limites da acção do Estado. Porto: Portugal. RESJURIDICA, 1990.

KANT, Immanuel. Resposta a pergunta: que é o iluminismo? In: A paz perpétua e outros opúsculos. Lisboa - Portugal: Edições 70, 2004.

Crítica da razão prática. São Paulo: Martins Fontes, 2008. 
MARX, Karl. Para a questão judaica. São Paulo: Expressão Popular, 2009. e ENGELS, Friedrich. A ideologia alemã. São Paulo: Editora HUCITEC, 1986.

MILL, John Stuart. Princípios de economia política. Volume III. São Paulo: Nova Cultural, 1988 (Os economistas).

Sobre a liberdade. Petrópolis, RJ: Vozes, 1991.

PONCE, Aníbal. Educação e luta de classe. São Paulo: Cortez, 1996.

SAVIANI, Dermeval. Educação socialista, pedagogia histórico-crítica e os desafios da sociedade de classes. In: LOMBARDI, José Claudinei e SAVIANI, Dermeval (Orgs.). Marxismo e educação: debates contemporâneos. Campinas, SP: Autores associados, 2008.

SAY. Jean-Baptiste. Tratado de economia política. São Paulo: Abril Cultural, 1983.

SMITH. Adam. A riqueza das nações: investigação sobre sua natureza e suas causas. Vol. II. São Paulo: Editora Nova Cultural. 1996.

SOUZA, Maria das Graças de. Apresentação. In: Cinco memórias sobre a instrução pública. Trad. de Maria das Graças de Souza. São Paulo: Editora da Unesp, 2008

TAMBARA, Elomar. Positivismo e educação: a educação no Rio Grande do Sul sob o castilhismo. Pelotas: Ed. Universitária/ UFPEL, 1995.

- Introdução à história da educação no Rio Grande do Sul. Pelotas: Universitária/Seiva, 2000.

THOUARD, Denis. Kant. São Paulo: Estação Liberdade, 2004.

\footnotetext{
1 UFPEL

2 Agradecemos ao colega professor Gelson Leonardo Rech pelas conversas e pelo empréstimo de artigos produzidos por ele, que ainda não haviam sido publicados e que muito nos ajudaram a compreender o pensamento de Kant.

${ }^{3}$ A instrução primária que num primeiro momento se estenderia a toda a população.

${ }^{4}$ Pode-se observar a presença do ideal Kantiano do uso público da razão (KANT, 2004).

${ }^{5}$ Barros (1986) e Chaves (2007).

6 Condorcet (1743 - 1794), Humboldt (1767 - 1835) e Mill (1806 - 1873).

7 Para Althusser (1974), o antigo Aparelho Ideológico dominante é o Aparelho Ideológico Religioso.
}

Recebido: $\quad$ outubro-13 Aprovado: março-14 